\title{
Previous Exposure to Nicotine Enhances the Incentive Motivational Effects of Amphetamine via Nicotine-Associated Contextual Stimuli
}

\author{
James J Cortright', Georgia R Sampedro', Nichole M Neugebauer' and Paul Vezina*,' \\ 'Department of Psychiatry and Behavioral Neuroscience, The University of Chicago, Chicago, IL, USA
}

\begin{abstract}
The effect of nicotine exposure on the subsequent self-administration of amphetamine, extinction of this behavior, and amphetamineinduced reinstatement of drug seeking was assessed with particular attention to the contribution of contextual stimuli paired or unpaired with nicotine during exposure. Rats were exposed to five injections, one injection every third day, of either saline or nicotine $(0.4 \mathrm{mg} / \mathrm{kg}, \mathrm{IP}$, base $)$ in three experiments. In one, exposure injections were administered in the home cage. In another, they were administered in the self-administration chambers with the levers retracted. In a third, nicotine was administered either explicitly paired or unpaired with the self-administration chambers using a discrimination learning procedure. Starting 13-15 days later, rats were trained to self-administer amphetamine ( $100 \mu \mathrm{g} / \mathrm{kg} /$ infusion, IV), tested under a progressive ratio (PR) schedule for 6 days, subjected to up to 20 days of extinction training, and were then tested for reinstatement by non-contingent injections of amphetamine $(0,0.2,0.4$, and $0.75 \mathrm{mg} / \mathrm{kg}, \mathrm{IP}$ ). Nicotine enhanced the self-administration of amphetamine under the PR schedule and amphetamine-induced reinstatement but only when rats were tested in the chamber in which they were previously exposed to nicotine. These effects were not observed in rats exposed to nicotine in the home cage or in rats exposed to nicotine explicitly unpaired with the self-administration chambers. Exposure to nicotine also rendered rats resistant to extinction when amphetamine was withheld but this effect was observed regardless of nicotine exposure context, suggesting a separate consequence of drug exposure. Together, these results show that previous exposure to nicotine can enhance the incentive motivational effects of other psychostimulants like amphetamine and indicate a critical role for nicotine-associated contextual stimuli in the mediation of this effect. These findings have important implications for the treatment of addictions in humans.

Neuropsychopharmacology (2012) 37, 2277-2284; doi: I0. I038/npp.2012.80; published online 23 May 2012
\end{abstract}

Keywords: conditioned inhibition; extinction; facilitation; reinstatement; self-administration; sensitization

\section{INTRODUCTION}

Nicotine and other psychomotor stimulants produce their behavioral effects, including self-administration, by activating the mesoaccumbens dopamine (DA) system. Nicotine acts at nicotine acetylcholine receptors (nAChRs) in the midbrain ventral tegmental area to increase locomotion and DA overflow in the nucleus accumbens and to support its self-administration (Vezina et al, 2007). Activation of nAChRs has also been implicated in the self-administration of other psychostimulants including cocaine and methamphetamine (Becktholt and Mark, 2002; Glick et al, 2002; Levin et al, 2000) as well as in cue-induced craving of cocaine in humans (Reid et al, 1999). These results suggest

*Correspondence: Dr P Vezina, Department of Psychiatry and Behavioral Neuroscience, The University of Chicago, 584I South Maryland Avenue, MC 3077, Chicago, IL 60637, USA, Tel: + I 773702 2890, Fax: + I 773702 0857, E-mail: pvezina@yoda.bsd.uchicago.edu

Received 4 April 2012; revised 24 April 2012; accepted 25 April 2012 not only a common neuronal pathway for the reinforcing actions of nicotine and other psychomotor stimulants, but also a critical role for nAChRs in the effects of other drugs.

As with other psychomotor stimulants (Vezina, 2004), rats repeatedly exposed to nicotine develop sensitization to its locomotor and nucleus accumbens DA-activating effects (Iyaniwura et al, 2001; Ksir et al, 1985; Schoffelmeer et al, 2002; Shim et al, 2001) as well as locomotor crosssensitization to amphetamine (Birrell and Balfour, 1998; Schoffelmeer et al, 2002). Again, nAChR activation is critical for the development of locomotor and dopaminergic sensitization by amphetamine and cocaine (Schoffelmeer et al, 2002) as well as cocaine-induced conditioned place preference (Zachariou et al, 2001). These results together with those from a number of epidemiological studies (Kandel, 2002; Kandel et al, 1992) have lent support to proposals that nicotine may serve as a gateway drug leading to the pursuit of other psychostimulants (Levine et al, 2011; Weinberger and Sofuoglu, 2009). Surprisingly few preclinical studies have investigated this possibility directly 
and to date, such studies have provided weak support for this view. Rats exposed to nicotine as adults subsequently showed enhanced acquisition of cocaine self-administration in one study (Horger et al, 1992) but no effects in another (McQuown et al, 2007). In two other studies assessing the effect of nicotine exposure on subsequent nicotine selfadministration, one reported modest effects limited to the first few days of acquisition under a fixed ratio 1 (FR1) schedule of reinforcement (Adriani et al, 2003) and another found mixed trends for enhancement and disruption (Shoaib et al, 1997). Multiple factors can influence the extent to which previous exposure to nicotine can affect subsequent drug-induced responding. These include the intensity of the exposure regimen and the withdrawal period between exposure and testing (Schoffelmeer et al, 2002; Vezina et al, 2007) as well as sex and age of the organism at the time of exposure and testing (Adriani et al, 2003; Collins et al, 2004; McQuown et al, 2007). A factor less often considered is the additional potential influence of drug-associated stimuli.

In the above experiments, adult rats exposed to nicotine in the self-administration chamber subsequently showed enhanced drug self-administration (Horger et al, 1992) while those exposed to nicotine in the home cage did not (Adriani et al, 2003; McQuown et al, 2007; Shoaib et al, 1997), suggesting that nicotine-paired contextual stimuli may have enabled the expression of enhanced drug self-administration resulting from previous exposure to nicotine. The ability of contextual stimuli to control the expression of sensitization to stimulant drugs is well established. As demonstrated in experiments with amphetamine, the presence of drug-paired or drug-unpaired stimuli during testing can regulate the intensity of the sensitized responses observed and in some cases determine whether sensitization is expressed at all (Anagnostaras and Robinson, 1996; Stewart and Vezina, 1988; Vezina and Leyton, 2009). Such stimuli have been shown to regulate the expression of locomotor and nucleus accumbens DA sensitization by nicotine as well (Reid et al, 1996, 1998). Given the demonstrated importance of drug-paired cues for the self-administration of low doses of cocaine (Schenk and Partridge, 2001) or a relatively weak primary reinforcer like nicotine (Caggiula et al, 2001), it is reasonable to expect that stimuli previously paired or unpaired with nicotine during exposure to the drug should also influence the subsequent selfadministration of nicotine and other psychostimulants. This possibility remains untested, although results consistent with this outcome have been reported. For example, contextual stimuli paired with nicotine self-administration have been shown to slow extinction of responding and reinstate drug seeking in animals (Diergaarde et al, 2008; Wing and Shoaib, 2008) and, in humans, to elicit craving to smoke (Conklin, 2006). The present preclinical experiments assessed the ability of contextual stimuli paired or unpaired with nicotine exposure injections to subsequently enable or inhibit enhanced responding for amphetamine.

\section{MATERIALS AND METHODS}

\section{Animals}

Male Long-Evans rats (Harlan Teklad, Madison, WI) weighing 250-275 g upon arrival were housed individually in a 12-h light/12-h dark reverse cycle room (lights off at 0700 hours and on at 1900 hours) with food and water freely available throughout the experiments. All procedures were conducted during the dark cycle according to protocols approved by the University of Chicago Institutional Animal Care and Use Committee. Drug injections were initiated at least $1 \mathrm{~h}$ into the dark cycle and administered at the same time of day throughout the experiments. All experiments were conducted in accordance with the Declaration of Helsinki and the Guide for the Care and Use of Laboratory Animals as adopted and promulgated by the National Institutes of Health.

\section{Apparatus}

Experimental sessions were conducted in 16 operant chambers (model H10-11R-TC, Coulbourn Instruments, Whitehall, PA) measuring $31 \times 25 \times 30 \mathrm{~cm}$. A single retractable lever $(6 \mathrm{~cm}$ above the floor) and a cue light $(13 \mathrm{~cm}$ above the lever) were positioned on the right side wall of each chamber. Each operant chamber was contained within a sound-attenuating chamber outfitted with an exhaust fan that shielded animals from extraneous disturbances. Each chamber was equipped with a counterbalanced arm, a steelspring tether, and an infusion pump (model PHM-100, Med Associates, St Albans, VT) that permitted free movement of the animal in the chamber and delivery of drug upon depression of the lever. Lever presses and drug infusions were recorded and controlled via an electrical interface by a computer using Med-Associates software.

\section{Drugs}

(-) Nicotine tartrate and $S(+)$-amphetamine sulfate were obtained from Sigma (St Louis, MO). Drugs were dissolved in sterile saline $(0.9 \% \mathrm{w} / \mathrm{v})$. The $\mathrm{pH}$ of the nicotine solution was adjusted to 7.0 with $\mathrm{NaOH}$.

\section{Surgery}

At the appropriate point in the experiments, rats were anesthetized with a mix of ketamine $(100 \mathrm{mg} / \mathrm{kg}$, IP) and xylazine $(6 \mathrm{mg} / \mathrm{kg}$, IP) and surgically implanted with an IV catheter into the right external jugular vein using procedures described previously (Pierre and Vezina, 1997). Catheters were made of silastic tubing (Dow Corning, Midland, MI) connected to a custom-designed L-shaped 20 gauge guide cannula (Plastics One, Roanoke, VA) that was passed subcutaneously to a small incision on the head and secured in place with dental cement anchored to skull screws. Catheters were subsequently flushed daily with a sterile $0.9 \%$ saline solution containing $30 \mathrm{IU} / \mathrm{ml}$ heparin and $250 \mathrm{mg} / \mathrm{ml}$ ampicillin in order to maintain patency.

\section{Design and Procedures}

As illustrated in Figure 1, experiments consisted of six phases: nicotine exposure, withdrawal and surgical preparation of rats, amphetamine self-administration training, amphetamine self-administration testing, extinction, and testing for amphetamine-primed reinstatement. 


\begin{tabular}{|c|c|c|c|c|c|}
\hline Nicotine & Withdrawal & Amphetamine & Amphetamine & Extinction & Amphetamine-Primed \\
\hline sure $\rightarrow$ & $\begin{array}{l}\text { IV catheter } \\
\text { Implant }\end{array}$ & $\rightarrow \underset{\text { Sraining }}{\text { Self-Admin }} \rightarrow$ & $\begin{array}{l}\text { PR Self-Admin } \\
\text { Testing }\end{array}$ & $\rightarrow$ & Reinstatement \\
\hline & (14 days) & (2-6 days) & (6 days) & (up to 20 days) & (1 day) \\
\hline
\end{tabular}

Figure I Outline of the experimental design showing the six different phases.

Exposure. Starting 3-5 days after arrival, rats were administered a total of five injections, one injection every third day, of either nicotine $(0.4 \mathrm{mg} / \mathrm{kg}$, IP; dose refers to the weight of the base) or saline. This injection regimen is known to sensitize rats to nicotine's locomotor and DA-activating effects (Vezina et al, 2007). In the present experiments, it was tested for its ability to enhance the subsequent self-administration of amphetamine. In order to assess the potential additional contribution of contextual stimuli paired or unpaired with nicotine during exposure on the subsequent self-administration of amphetamine, exposure injections were administered in different environments to rats in different groups. In one case, nicotine and saline injections were administered to rats in different groups in the home cage (NIC HOME CAGE; SAL HOME CAGE). In another, injections were administered in the selfadministration chambers with the levers retracted (NIC SA CHAMBER; SAL SA CHAMBER). In this case, rats remained in the self-administration chambers for $2 \mathrm{~h}$ following each injection. For rats administered nicotine, the cue light was illuminated for the entire $2 \mathrm{~h}$. Finally, rats in two additional groups were administered nicotine either Paired or Unpaired with the self-administration chambers (NIC PAIRED; NIC UNPAIRED). Paired rats were administered nicotine in the self-administration chambers on 1 day, saline in the home cage on the following day, and were left undisturbed in their home cage on the third day. This 3-day block was repeated five times. Unpaired rats were administered these injections in the reverse order: saline in the self-administration chambers and nicotine in the home cage. Injections made in the self-administration chambers were as described above. This discrimination learning procedure is known to establish a contextual stimulus complex (ie, the self-administration chamber) not only as an excitatory conditioned stimulus $(\mathrm{CS}+)$ when it is explicitly paired with the drug in the case of the Paired rats but also as a conditioned inhibitor (CI) when it is explicitly unpaired with the drug in the case of Unpaired rats (Mackintosh, 1974; Vezina and Leyton, 2009).

Withdrawal. Following the 13-15 day drug exposure phase, rats were afforded a 2-week procedure and drug-free period. During this time, they were surgically prepared with an IV catheter and left to recover for at least 5 days before selfadministration training.

Amphetamine self-administration training. Amphetamine self-administration sessions were held daily and lasted for a maximum of $3 \mathrm{~h}$. In all cases, reinforced lever presses delivered an infusion of amphetamine through the IV catheter $(100 \mu \mathrm{g} / \mathrm{kg} / \mathrm{infusion}$; dose refers to weight of the salt) delivered in a volume of $0.09-0.11 \mathrm{ml} /$ infusion at a rate of $1.065 \mathrm{ml} / \mathrm{min}$. For $10 \mathrm{~s}$ immediately following a reinforced
Table I Mean \pm SEM Days to Criterion for Amphetamine SelfAdministration Training

\begin{tabular}{lcc}
\hline Exposure group & Days to criterion & \\
\hline SAL HOME CAGE $(n=16)$ & $2.75 \pm 0.28$ & \\
NIC HOME CAGE $(n=13)$ & $2.77 \pm 0.34$ & $t(27)=0.14$, NS \\
SAL SA CHAMBER $(n=9)$ & $2.56 \pm 0.29$ & \\
NIC SA CHAMBER $(n=8)$ & $3.38 \pm 0.53$ & $t(15)=1.31$, NS \\
NIC UNPAIRED $(n=9)$ & & \\
NIC PAIRED $(n=8)$ & $2.56 \pm 0.29$ & $t(15)=0.12, N S$ \\
\hline
\end{tabular}

Abbreviation: NS, not statistically significant.

Minimum possible days to criterion was $2(F R I=I$ and $F R 2=1$ ); maximum was $10(F R I=5$ and $F R 2=5)$.

lever press, the cue light above the lever was lit and lever presses were recorded but without consequence. An experimenter-delivered priming infusion of amphetamine $(100 \mu \mathrm{g} / \mathrm{kg}, \mathrm{IV})$ was given at the beginning of each session. The initial schedule used was an FR1 schedule of reinforcement and it was increased to an FR2 schedule once animals successfully administered an additional nine infusions within the 3-h session. Animals were then again required to self-administer an additional nine infusions within a 3-h session under the FR2 schedule. This procedure kept exposure to amphetamine during self-administration training to a minimum so as not to compromise existing group differences in nicotine exposure history (Table 1; Vezina, 2004; Vezina et al, 2002). Animals that did not satisfy each of the FR1 and the FR2 criteria within 5 days were excluded from the study. Six rats were thus excluded (NIC HOME CAGE, 1; SAL HOME CAGE, 1; NIC SA CHAMBER, 1; NIC PAIRED, 1; NIC UNPAIRED, 2). Days to satisfaction of the training criteria were recorded.

Amphetamine self-administration testing. Upon satisfactory completion of self-administration training under the FR schedules, rats were tested daily under a progressive ratio (PR) schedule of reinforcement for 6 days as described previously (Vezina et al, 2002). Under this schedule, the number of responses required to obtain each successive infusion of amphetamine was determined by ROUND(5$\operatorname{XEXP}(0.25 \times$ infusion number $)-5)$ to produce the following sequence of required lever presses: $1,3,6,9,12,17,24,32$, $42,56,73,95,124,161,208$, and so on (Richardson and Roberts, 1996). In preliminary experiments using this exponential function with the dose of amphetamine selfadministered in the present experiments $(100 \mu \mathrm{g} / \mathrm{kg} / \mathrm{infu}-$ sion, IV), it was found that the time of the last infusion 
occurred on average in $<2 \mathrm{~h}$. The daily PR sessions were thus terminated after 3 -h or after 1 -h elapsed without a drug infusion. Priming amphetamine infusions were not given during these sessions. The number of lever presses and infusions obtained in each PR session was recorded.

Extinction. Starting the day after the amphetamine selfadministration testing phase, all rats were subjected to daily extinction sessions during which amphetamine was withheld and the cue light alone was presented under the PR schedule. Each session lasted $3-\mathrm{h}$ or less if 1 -h elapsed without presentation of the cue light. The extinction criterion was set at 10 or fewer lever presses in each of two consecutive sessions. After meeting this criterion or after undergoing 20 daily extinction sessions, rats were moved on to the final phase of the experiment, testing for amphetamine-primed reinstatement. The number of lever presses emitted during each session and the number of sessions required to meet the extinction criterion were recorded. Nine rats were excluded because of illness or dislocated head mounts during this phase (NIC HOME CAGE, 3; SAL HOME CAGE, 3; NIC SA CHAMBER, 1; SAL SA CHAMBER, 1; NIC UNPAIRED, 1).

Test for amphetamine-primed reinstatement. This test was conducted on the day following the last extinction session. On this test, rats were first subjected to a 3-h extinction session in which both amphetamine and cue light presentations were withheld. They were then tested for reinstatement primed by amphetamine injections $(0,0.20$, 0.40 , and $0.75 \mathrm{mg} / \mathrm{kg}$, IP) during four 1 -h sessions each separated by $5 \mathrm{~min}$. Saline and amphetamine injections were administered just before the 1-h test sessions in an ascending order to minimize carry-over effects of residual amphetamine. All lever presses on this test were without consequence. The number of lever presses on the third hour of the extinction session and during each subsequent 1 -h priming session was recorded. Three final rats were excluded because of illness or dislocated head mounts during this phase (SAL SA CHAMBER, 2; NIC UNPAIRED, 1).

\section{Data Analyses}

The data obtained in the three different experiments (HOME CAGE exposure; SA CHAMBER exposure; PAIRED/UNPAIRED exposure) were analyzed separately. Independent samples $t$-tests were used to analyze days to satisfaction of the training criteria during amphetamine self-administration training as well as number of days to meet the extinction criterion and number of lever presses emitted on the last day of extinction. Between-within ANOVA with exposure (two levels: nicotine and saline or nicotine paired and unpaired) as the between factor and test days ( 6 days) as the within factor were used to analyze the number of infusions obtained on the six amphetamine selfadministration test days. Similarly, between-within ANOVA with exposure (two levels: nicotine and saline or nicotine paired and unpaired) as the between factor and hours of testing $(5 \mathrm{~h})$ as the within factor were used to analyze the number of lever presses emitted on the 5-h test for amphetamine-primed reinstatement. When required, posthoc comparisons were made using the Scheffé test according to Kirk (1968). Finally, the proportion of rats that failed to meet the extinction criterion after 20 sessions was calculated for the different exposure groups and compared in each experiment using the $\chi^{2}$ test for two independent samples.

\section{RESULTS}

\section{Amphetamine Self-Administration Training}

In agreement with previous results obtained following amphetamine exposure (Lorrain et al, 2000; Vezina et al, 2002), rats exposed to nicotine either in the home cage or the self-administration chambers did not differ from their saline-exposed counterparts in days to criterion during amphetamine self-administration training. Similarly, rats exposed to nicotine either paired or unpaired with the selfadministration chambers did not differ from one another (Table 1).

\section{Amphetamine Self-Administration Testing}

Exposure to nicotine enhanced the subsequent self-administration of amphetamine under the PR schedule of reinforcement but only when rats were tested in the chamber they were previously exposed to nicotine in. In addition, rats exposed to nicotine explicitly unpaired with these chambers failed to show enhanced amphetamine selfadministration (Figure 2). Analysis by ANOVA of the number of amphetamine infusions obtained over the 6-test days revealed no significant effects when rats were administered their exposure injections in the home cage (Figure 2a). When exposure injections were administered in the self-administration chambers (Figure 2b), nicotineexposed rats obtained significantly more amphetamine infusions over the 6 days of testing than their salineexposed counterparts $(\mathrm{F}(1,15)=8.93, p<0.01)$. Finally, rats exposed to nicotine explicitly unpaired with the selfadministration chambers (Figure 2c) obtained significantly fewer infusions compared with rats exposed to nicotine paired with the chambers $(\mathrm{F}(1,15)=6.06, p<0.05)$ and showed levels of responding comparable to rats exposed to saline either in the home cage or the self-administration chambers (Figures $2 \mathrm{a}$ and $\mathrm{b}$ ).

\section{Extinction}

Figure 3 illustrates the effects of previous exposure to nicotine on the extinction of amphetamine self-administration. Consistent with the effects observed during amphetamine self-administration testing under the PR schedule, nicotine exposure rendered rats resistant to extinction. Unlike the above findings, however, this effect was observed regardless of nicotine exposure context. Relative to their saline-exposed controls, rats exposed to nicotine in the home cage (Figures $3 a$ and $d$ ) showed a greater number of days to meet the extinction criterion $(t(21)=1.98, p<0.05)$ and a greater number of lever presses on the last day of extinction $(t(21)=2.40, p<0.05)$. Rats exposed to nicotine in the self-administration chambers (Figures $3 b$ and e) exhibited similar effects relative to their saline-exposed 

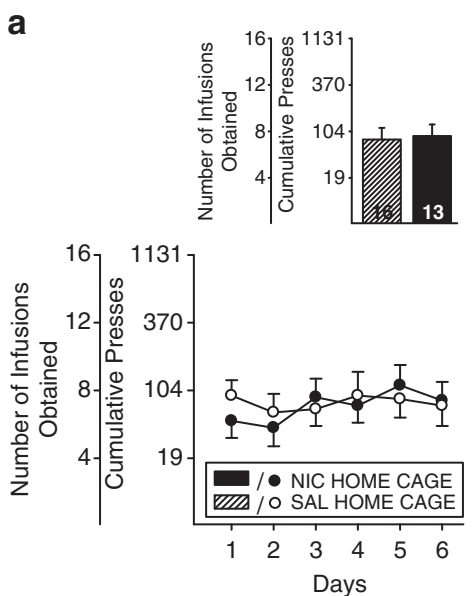

b
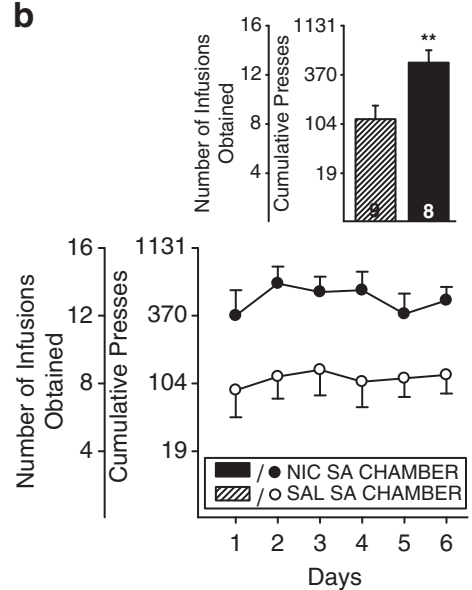
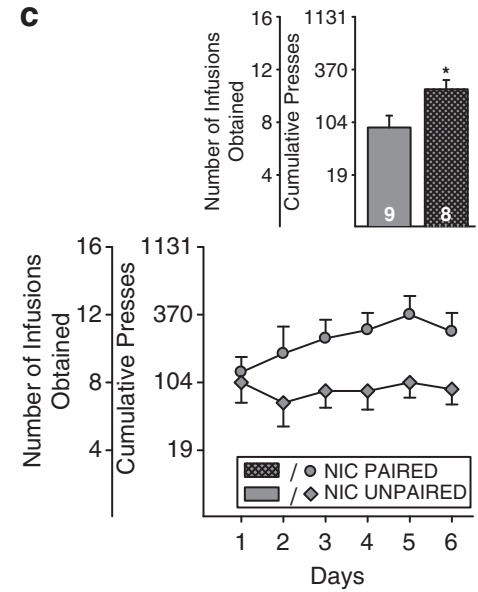

Figure 2 Previous exposure to nicotine in the drug-taking environment enhances the subsequent self-administration of amphetamine under a PR schedule of reinforcement. Data are shown as mean ( \pm SEM) number of amphetamine infusions obtained over the 6 days of testing. The cumulative number of lever presses required to obtain these infusions is also shown. The bar graphs (means + SEM) in the insets were derived from the means of the values obtained for each subject on each of the six PR test days. Numbers at the bottom of each bar indicate $n$ per group. Exposure injections were made in the home cage (a), the self-administration (SA) chambers with the levers retracted (b), or either explicitly paired or unpaired with the SA chambers (c). * $p<0.05$, compared with NIC UNPAIRED. *** $<0.01$, compared with saline exposed.
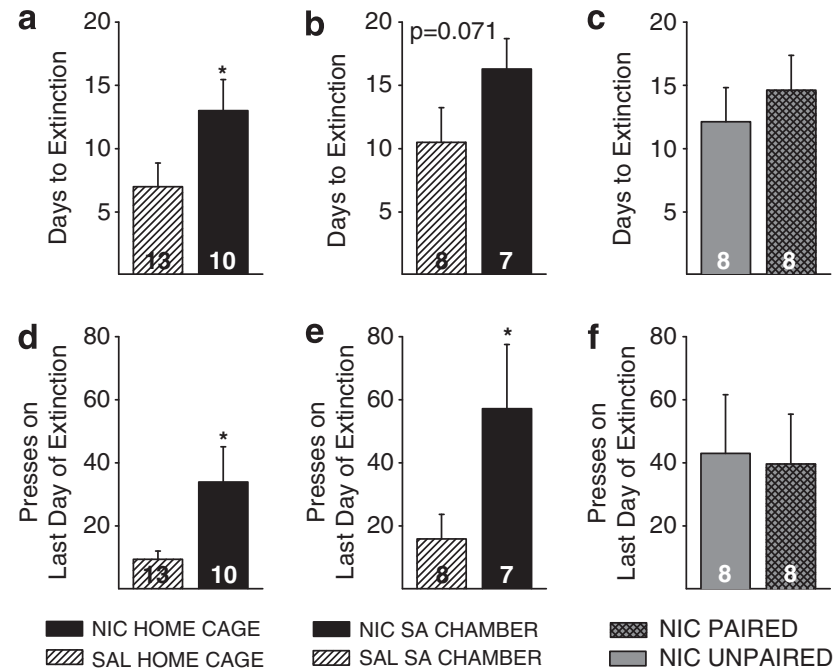

Figure 3 Previous exposure to nicotine rendered rats resistant to extinction regardless of nicotine exposure context. Data are shown as mean $(+$ SEM) number of days in extinction training $(a-c)$ and presses on the last day of extinction $(\mathrm{d}-\mathrm{f})$. Exposure injections were made in the home cage $(a, d)$, the SA chambers (b, e), or either explicitly paired or unpaired with the SA chambers (c, f). Numbers at the bottom of each bar indicate $n$ per group. $* 0<0.05$, compared with saline exposed.

controls, showing a nonsignificant trend for more days to extinction $(t(13)=1.57, p=0.071)$ and significantly more lever presses on the last day of extinction $(t(13)=1.99$, $p<0.05)$. No significant group differences were observed in either measure in rats exposed to nicotine paired or unpaired with the self-administration chambers (Figures $3 \mathrm{c}$ and $\mathrm{f}$ ). Rats in these groups showed levels of responding similar to the above nicotine-exposed rats. $\chi^{2}$ analyses of the proportion of rats failing to meet the extinction criterion in the different groups revealed a significantly greater number of failures in nicotine (4/10) relative to saline (1/13) exposed rats $(p<0.05)$ in the home cage exposure condition. Similarly, relative to their saline exposure controls
$(2 / 8)$, significantly more nicotine-exposed rats (5/7) failed to meet this criterion $(p<0.01)$ in the self-administration chamber exposure condition. Rats in the Paired and Unpaired nicotine exposure groups did not differ from each other in this measure.

\section{Test for Amphetamine-Primed Reinstatement}

Similar to what was observed during amphetamine selfadministration testing, exposure to nicotine enhanced the ability of amphetamine priming injections to reinstate drug seeking but only when rats were tested in the environment in which they were previously exposed to nicotine. Again, amphetamine-induced reinstatement was not enhanced when rats were tested in chambers explicitly unpaired with nicotine during exposure (Figure 4). Analysis by ANOVA of the number of lever presses emitted on this test showed a significant effect of priming injections under all context exposure conditions: home cage $(\mathrm{F}(4,84)=4.54, p<0.01)$, self-administration chamber $(\mathrm{F}(4,44)=4.76, p<0.01)$, and paired/unpaired $(\mathrm{F}(4,52)=10.71, p<0.001)$. Post-hoc Scheffé comparisons revealed that compared with levels observed in the last hour of extinction, the amphetamine priming injections significantly increased lever pressing in rats exposed to nicotine in the self-administration chambers $(p<0.05)$ but not in the home cage. This effect was also observed in rats exposed to nicotine paired $(p<0.01)$ but not in rats exposed to nicotine unpaired with the chambers.

\section{DISCUSSION}

In the present experiments, exposure to nicotine enhanced the subsequent self-administration of amphetamine under a $\mathrm{PR}$ schedule, rendered rats resistant to extinction when amphetamine was withheld, and enhanced the reinstatement of amphetamine-primed drug seeking. These results show that previous exposure to nicotine can enhance the incentive motivational effects of other psychostimulants like 

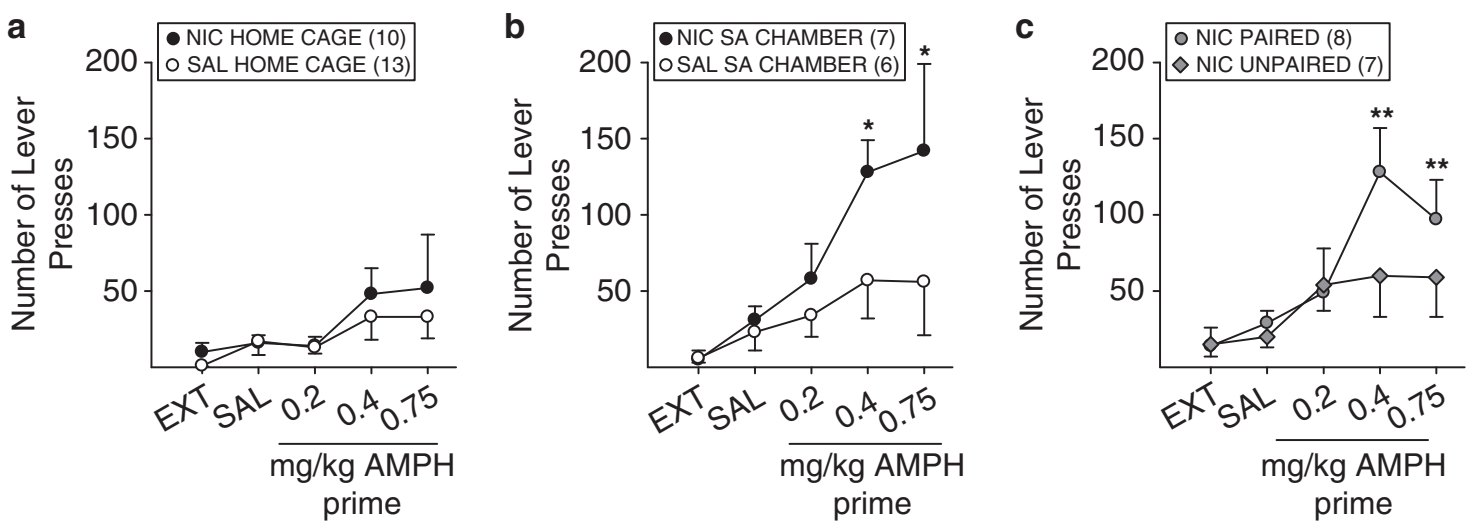

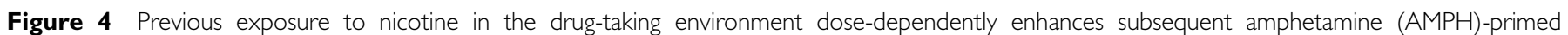

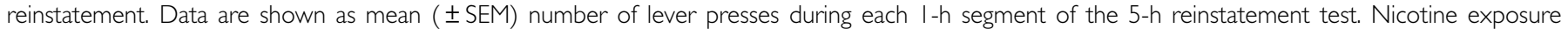
contexts are as described in Figure 2. ${ }^{*} p<0.05$, ** $p<0.01$, compared with the last hour of the extinction component of this test as revealed by Scheffé post-hoc comparisons following ANOVA.

amphetamine. The finding that amphetamine self-administration and reinstatement were enhanced only when rats were tested in the chamber in which they were previously exposed to nicotine indicates a critical role for nicotinepaired contextual stimuli in the mediation of these effects.

Repeated intermittent exposure to nicotine, a pattern often associated with initial exposure to tobacco, leads to sensitization of its locomotor and nucleus accumbens DAactivating effects (Iyaniwura et al, 2001; Ksir et al, 1985; Schoffelmeer et al, 2002; Shim et al, 2001) and has been shown to produce locomotor cross-sensitization to amphetamine (Birrell and Balfour, 1998; Schoffelmeer et al, 2002). The present results extend these findings to include the enhancement of amphetamine self-administration by previous nicotine exposure. They are consistent with incentive motivational views of enhanced drug taking (Robinson and Berridge, 1993; Stewart et al, 1984) and with a number of reports showing that exposure to a regimen of drug injections known to sensitize midbrain DA neuron reactivity leads to a long-lasting increase in the predisposition to pursue these and other drugs (Vezina, 2004; Vezina et al, 2007). Importantly, exposure to a drug like $\Delta^{9}$-THC that does not alter subsequent nucleus accumbens DA overflow in response to amphetamine does not enhance the subsequent self-administration of amphetamine (Cortright et al, 2011). Together, these results support suggestions by some that exposure to nicotine may induce changes in the mesoaccumbens DA system (Kandel et al, 1994) that increase individuals' predisposition to pursue it and other drugs (Kandel, 2002; Kandel et al, 1992; Levine et al, 2011; Weinberger and Sofuoglu, 2009).

The ability of contextual stimuli previously associated with a drug to regulate the expression of sensitized locomotion and nucleus accumbens DA overflow by nicotine (Reid et al, 1996, 1998) and amphetamine (Anagnostaras and Robinson, 1996; Guillory et al, 2006; Stewart and Vezina, 1988; Vezina and Leyton, 2009), and locomotor cross-sensitization from one drug to another (Stewart and Vezina, 1987; Vezina et al, 1989) is well established. The present findings show that such contextual stimuli can also regulate the expression of enhanced drug self-administration and the reinstatement of drug seeking.
They are consistent with those of Horger et al (1992) who reported that rats exposed to nicotine in the self-administration chamber subsequently show enhanced drug selfadministration in this environment and provide an explanation for the failure of others to observe this effect (Adriani et al, 2003; McQuown et al, 2007; Shoaib et al, 1997). In these latter reports, rats were exposed to nicotine in their home cage and were subsequently tested in the selfadministration chambers where they did not show enhanced drug self-administration. Together, these results suggest that contextual stimuli previously paired with nicotine can enhance the incentive motivational effects of other psychostimulants and thus promote enhanced drug self-administration and reinstatement of drug seeking. Indeed, such contextual stimuli are well known to increase craving to smoke in humans (Conklin, 2006). As noted earlier, multiple factors can influence the extent to which previous exposure to nicotine can affect subsequent druginduced responding. The different nicotine exposure regimens and withdrawal times used in the present experiments and above reports likely contributed in different ways. The present findings indicate that nicotine-paired contextual stimuli can be critical determinants of the effects ultimately observed.

The prevailing evidence suggests that contextual stimuli paired or unpaired with drug exposure can regulate the expression of sensitization by respectively acting as facilitators to enable it (Anagnostaras and Robinson, 1996) or as CIs to suppress it (Stewart, 1992; Stewart and Vezina, 1988; see Vezina and Leyton, 2009). Our results suggest that both mechanisms may have participated in the present experiments. The self-administration chambers clearly enabled the expression of enhanced amphetamine self-administration and reinstatement in rats previously exposed to nicotine in this context (NIC SA CHAMBER); these effects were not observed when the nicotine-paired stimuli were not present (in rats exposed to nicotine in the home cage; NIC HOME CAGE). It is unlikely that the enhanced responding observed was due to the accrual of excitatory contextual conditioning of drug-taking responses by nicotine and their summation with the amphetamineinduced behaviors. Rats were trained to emit a novel 
response (lever press) to self-administer amphetamine and this was done 2 weeks after exposure to nicotine. In addition, there was no evidence that prior exposure to nicotine or nicotine-paired stimuli enhanced conditioning of the lever press response (Olausson et al, 2003) as no group differences were detected in its acquisition. The discrimination learning procedure used in the NIC PAIRED/UNPAIRED experiment is known to establish a contextual stimulus complex (the self-administration chamber) not only as a conditioned facilitator when it is explicitly paired with the drug in the case of the Paired rats but also as a CI when it is explicitly unpaired with the drug in the case of Unpaired rats (Mackintosh, 1974; Vezina and Leyton, 2009). The lack of enhanced amphetamine selfadministration and reinstatement observed in rats exposed to nicotine explicitly unpaired with the self-administration chambers in the present experiment could thus also have resulted from inhibition of these effects by the CI properties of these contextual stimuli. This possibility is supported by reports showing that removal of this inhibition allows the expression of sensitized responding in rats tested in the previously drug unpaired environment (Anagnostaras et al, 2002; Stewart and Vezina, 1991). Together, these results show powerful excitatory and inhibitory associative control over the expression of enhanced drug taking and seeking with important implications for the treatment of addictions in humans.

Repeated intermittent drug exposure provides many opportunities for the formation of associations between the drug and multiple environmental stimuli. The present findings stress the need to identify the relevant associations, determine how they interact with other factors, and decipher how they can subsequently regulate behavior. Drug-context associations may be particularly important regulators of drug-taking and -seeking behaviors. For example, while locomotor sensitization by nicotine and its cross-sensitization to amphetamine can be expressed in a context-independent manner (Schoffelmeer et al, 2002), nicotine-associated contextual stimuli were found to be necessary for the expression of enhanced amphetamine selfadministration and amphetamine-primed reinstatement in the present experiments. This does not preclude the possibility that nicotine also influences self-administration behaviors in a manner independent of contextual conditioning. Indeed, the ability of nicotine to interact associatively and non-associatively with non-pharmacological stimuli has been described (Caggiula et al, 2009) and exposure to nicotine in the home cage has been shown to enhance lever pressing for a tone-light conditioned reinforcer (Olausson et al, 2004). Consistent with these results, previous exposure to nicotine enhanced responding for the amphetamine-paired cue light during extinction in the present experiments regardless of nicotine exposure context. Although these non-associative effects clearly provide an important mechanism by which nicotine exposure can affect motivated behaviors, it remains to be determined how they relate to the associative effects regulating drug self-administration and reinstatement observed in the present experiments, what potentially independent substrates underlie the two types of effects, and how these are differentially recruited. Interestingly, unlike what is seen in adults, rats exposed to nicotine as adolescents appear more sensitive to the drug but less sensitive to contextual stimuli when subsequently tested for drug self-administration (Adriani et al, 2003; McQuown et al, 2007). This may reflect a critical developmental factor putting younger individuals at greater risk for later unregulated vulnerability for addiction. In individuals exposed to nicotine as adults, drug-paired and -unpaired contextual stimuli may thus have a more important role to enable or inhibit enhanced responding for nicotine and other drugs.

\section{ACKNOWLEDGEMENTS}

This study was supported by National Institutes of Health Grants P01 DA019695, RO1 DA09397, and T32 DA07255.

\section{DISCLOSURE}

The authors declare no conflict of interest.

\section{REFERENCES}

Adriani W, Spijker S, Deroche-Gamonet V, Laviola G, Le Moal M, Smit A et al (2003). Evidence for enhanced neurobehavioral vulnerability to nicotine during periadolescence in rats. $J$ Neurosci 23: 4712-4716.

Anagnostaras SG, Robinson TE (1996). Sensitization to the psychomotor stimulant effects of amphetamine: modulation by associative learning. Behav Neurosci 110: 1397-1414.

Anagnostaras SG, Schallert T, Robinson TE (2002). Memory processes governing amphetamine-induced psychomotor sensitization. Neuropsychopharmacology 26: 703-715.

Becktholt AJ, Mark GP (2002). Enhancement of cocaine-seeking behavior by repeated nicotine exposure in rats. Psychopharmacology 162: 178-185.

Birrell CE, Balfour DJK (1998). The influence of nicotine pretreatment on mesoaccumbens dopamine overflow and locomotor responses to D-amphetamine. Psychopharmacology 140: 142-149.

Caggiula AR, Donny EC, Palmatier MI, Liu X, Chaudhri N, Sved AF (2009). The role of nicotine in smoking: a dual-reinforcement model. In: Bevins RA, Caggiula AR (eds) The Motivational Impact of Nicotine and its Role in Tobacco Use. Springer: New York, pp 91-109.

Caggiula AR, Donny EC, White AR, Chaudhri N, Booth S, Gharib MA et al (2001). Cue dependency of nicotine self-administration and smoking. Pharmacol Biochem Behav 70: 515-530.

Collins SL, Montano R, Izenwasser S (2004). Nicotine treatment produces persistent increases in amphetamine-stimulated locomotor activity in periadolescent male but not female or adult male rats. Dev Brain Res 153: 175-187.

Conklin CA (2006). Environments as cues to smoke: implications for human extinction-based research and treatment. Exp Clin Psychopharmacol 14: 12-19.

Cortright JJ, Lorrain DS, Beeler JA, Tang W-J, Vezina P (2011). Previous exposure to $\Delta^{9}$-tetrahydrocannibinol enhances locomotor responding to but not self-administration of amphetamine. J Pharmacol Exp Ther 337: 724-733.

Diergaarde L, de Vries W, Raaso H, Schoffelmeer ANM, De Vries TJ (2008). Contextual renewal of nicotine seeking in rats and its suppression by the cannabinoid-1 receptor antagonist Rimonabant (SR141716A). Neuropharmacology 55: 712-716.

Glick SD, Maisonneuve IM, Kitchen BA, Fleck MW (2002). Eur J Pharmacol 438: 99-105.

Guillory AM, Suto N, You Z-B, Vezina P (2006). Effects of conditioned inhibition on neurotransmitter overflow in the nucleus accumbens. Soc Neurosci Abstr 32: 483.3. 
Horger BA, Giles MK, Schenk S (1992). Preexposure to amphetamine and nicotine predisposes rats to self-administer a low dose of cocaine. Psychopharmacology 107: 271-276.

Iyaniwura TT, Wright AE, Balfour DJK (2001). Evidence that mesoaccumbens dopamine and locomotor responses to nicotine in the rat are influenced by pretreatment dose and strain. Psychopharmacology 158: 73-79.

Kandel DB (2002). Examining the gateway hypothesis: stages and pathways of drug involvement. In: Kandel DB (ed) Stages and Pathways of Drug Involvement: Examining the Gateway Hypothesis. Cambridge University Press: Cambridge, UK, pp 3-9.

Kandel DB, Wu P, Davies M (1994). Maternal smoking during pregnancy and smoking by adolescent daughters. Am J Pub Health 84: 1407-1413.

Kandel DB, Yamaguchi K, Chen K (1992). Stages of progression in drug involvement from adolescence to adulthood: further evidence for the gateway theory. J Stud Alcohol 53: 447-457.

Kirk RE (1968). Experimental Design: Procedures for the Behavioral Sciences. Brooks/Cole: Pacific Grove, CA.

Ksir C, Hakan R, Hall Jr DP, Kellar KJ (1985). Exposure to nicotine enhances the behavioral stimulant effect of nicotine and increases binding of $[3 \mathrm{H}]$ acetylcholine to nicotine receptors. Neuropharmacology 24: 527-531.

Levin ED, Mead T, Rezvani AH, Rose JE, Gallivan C, Gross R (2000). The nicotinic antagonist mecamylamine preferentially inhibits cocaine vs. food self-administration in rats. Physiol Behav 71: 565-570.

Levine A, Huang YY, Drisaldi B, Griffin Jr EA, Pollak DD, Xu S et al (2011). Molecular mechanism for a gateway drug: epigenetic changes initiated by nicotine prime gene expression by cocaine. Sci Transl Med 3: 1-10.

Lorrain DS, Arnold GM, Vezina P (2000). Previous exposure to amphetamine increases incentive to obtain the drug: long-lasting effects revealed by the progressive ratio schedule. Behav Brain Res 107: 9-19.

Mackintosh NJ (1974). The Psychology of Animal Learning. Academic Press: New York, NY.

McQuown SC, Belluzzi JD, Leslie FM (2007). Low dose nicotine treatment during early adolescence increases subsequent cocaine reward. Neurotoxicol Teratol 29: 66-73.

Olausson P, Jentsch JD, Taylor JR (2003). Repeated nicotine exposure enhances reward-related learning in the rat. Neuropsychopharmacology 28: 1264-1271.

Olausson P, Jentsch JD, Taylor JR (2004). Repeated nicotine exposure enhances responding with conditioned reinforcement. Psychopharmacology 173: 98-104.

Pierre PJ, Vezina P (1997). Predisposition to self-administer amphetamine: the contribution of response to novelty and prior exposure to the drug. Psychopharmacology 129: 277-284.

Reid MS, Ho LB, Berger SP (1996). Effects of environmental conditioning on the development of nicotine sensitization: behavioral and neurochemical analysis. Psychopharmacology 126: 301-310.

Reid MS, Ho LB, Berger SP (1998). Behavioral and neurochemical components of nicotine sensitization following 15-day pretreatment: studies on contextual conditioning. Behav Pharmacol 9: 137-148.

Reid MS, Mickalian JD, Delucchi KL, Berger SP (1999). A nicotine antagonist, mecamylamine, reduces cue-induced cocaine craving in cocaine-dependent subjects. Neuropsychopharmacology 20: 297-307.
Richardson NR, Roberts DCS (1996). Progressive ratio schedules in drug self-administration studies in rats: a method to evaluate reinforcing efficacy. J Neurosci Meth 66: 1-11.

Robinson TE, Berridge KC (1993). The neural basis of drug craving: an incentive-sensitization theory of addiction. Brain Res Rev 18: 247-291.

Schenk S, Partridge B (2001). Influence of a conditioned light stimulus on cocaine self-administration in rats. Psychopharmacology 154: 390-396.

Schoffelmeer ANM, De Vries TJ, Wardeh G, van de Ven HWM, Vanderschuren LJMJ (2002). Psychostimulant-induced behavioral sensitization depends on nicotinic receptor activation. J Neurosci 22: 3269-3276.

Shim I, Javaid JI, Wirtshafter D, Jang S-Y, Shin K-H, Lee H-J et al (2001). Nicotine-induced behavioral sensitization is associated with extracellular dopamine release and expression of c-Fos in the striatum and nucleus accumbens of the rat. Beh Brain Res 121: 137-147.

Shoaib M, Schindler CW, Goldberg SR (1997). Nicotine selfadministration in rats: strain and nicotine pre-exposure effects on acquisition. Psychopharmacology 129: 35-43.

Stewart J (1992). Neurobiology of conditioning to drugs of abuse. In: Kalivas PW, Samson HH (eds) The Neurobiology of Drug and Alcohol Addiction. New York Academy of Sciences: New York, pp 335-346.

Stewart J, de Wit H, Eikelboom R (1984). Role of unconditioned and conditioned drug effects in the self-administration of opiates and stimulants. Psychol Rev 91: 251-268.

Stewart J, Vezina P (1987). Environment-specific enhancement of the hyperactivity induced by systemic or intra-VTA morphine injections in rats pre-exposed to amphetamine. Psychobiology 15: 144-153.

Stewart J, Vezina P (1988). Conditioning and behavioral sensitization. In: Kalivas PW, Barnes CD (eds) Sensitization in the Nervous System. Telford Press: Caldwell, NJ, pp 207-224.

Stewart J, Vezina P (1991). Extinction procedures abolish conditioned stimulus control but spare sensitized responding to amphetamine. Behav Pharmacol 2: 65-71.

Vezina P (2004). Sensitization of midbrain dopamine neuron reactivity and the self-administration of psychomotor stimulant drugs. Neurosci Biobehav Rev 27: 827-839.

Vezina P, Giovino AA, Wise RA, Stewart J (1989). Environmentspecific cross-sensitization between the locomotor activating effects of morphine and amphetamine. Pharmacol Biochem Beh 32: $581-584$.

Vezina P, Leyton M (2009). Conditioned cues and the expression of sensitization in animals and humans. Neuropharmacology 56: 160-168.

Vezina P, Lorrain DS, Arnold GM, Austin JD, Suto N (2002). Sensitization of midbrain dopamine neuron reactivity promotes the pursuit of amphetamine. J Neurosci 22: 4654-4662.

Vezina P, McGehee DS, Green WN (2007). Exposure to nicotine and sensitization of nicotine-induced behaviors. Prog NeuroPsychopharmacol Biol Psychi 31: 1625-1638.

Weinberger AH, Sofuoglu M (2009). The impact of cigarette smoking on stimulant addiction. Am J Drug Alcohol Abuse 35: 12-17.

Wing VC, Shoaib M (2008). Contextual stimuli modulate extinction and reinstatement in rodents self-administering intravenous nicotine. Psychopharmacology 200: 357-365.

Zachariou V, Caldarone BJ, Weathers-Lowin A, George TP, Elsworth JD, Roth RH et al (2001). Nicotine receptor inactivation decreases sensitivity to cocaine. Neuropsychopharmacology 24: 576-589. 